\title{
The Impact of Teacher Questioning on Creating Interaction in EFL: A Discourse Analysis
}

\author{
Mona Yousef Al-Zahrani ${ }^{1} \&$ Abdullah Al-Bargi ${ }^{2}$ \\ ${ }^{1}$ English Language Institute, King Abdulaziz University, Jeddah, Saudi Arabia \\ ${ }^{2}$ English Language Institute, King Abdulaziz University, Jeddah, Saudi Arabia \\ Correspondence: Mona Yousef Al-Zahrani, English Language Institue, King Abdulaziz University, P. O. Box \\ 80200, Jeddah, 21589, Saudi Arabia. E-mail: myalzahrani@kau.edu.sa
}

Received: March 1, 2017 Accepted: May 20, 2017 Online Published: May 26, 2017

doi: 10.5539/elt.v10n6p135 URL: http://doi.org/10.5539/elt.v10n6p135

\begin{abstract}
This study examines the effect of questions on fostering interaction in English as a Foreign Language (EFL) classrooms. It also seeks to determine the characteristics of questions that promote increased classroom interaction. Data were collected through video recordings of EFL classrooms which were analyzed using Discourse Analysis techniques. Participants in the study are consisted of a group of intermediate-level English students at the English Language Institute (ELI) of a Saudi Arabian university. First, participating classes were video-recorded and the data gathered was transcribed. The questions asked in each class were then divided into two groups: questions that were deemed to promote classroom interaction and questions that failed to create classroom interaction. Finally, the defining features of each group of questions were determined. Results showed a correlation between the questions' characteristics and the creation of classroom interaction. In other words, some question types significantly improved classroom interaction while others failed to do so.
\end{abstract}

Keywords: teacher questioning, interaction in EFL classrooms, discourse analysis, Saudi Arabia

\section{Introduction}

Recent researches in the field of second language acquisition (SLA) have been concerned with investigating verbal questioning behavior and the techniques used in ESL/EFL classrooms as they tend to serve different purposes, including simply checking for understanding, looking for unknown answers, or getting learners to produce language (Long \& Sato, 1983). Classroom interaction involves a significant number of teacher questions directed to learners (Brown, 2006). Richards (2003) claimed that the act of verbal questioning and answering that occurs between teacher and student is more frequent than any other event in EFL classrooms. According to Dalton-Puffer (2007), instructions that include posing verbal questions during lessons are more effective in producing achievement gains than instructions carried out without questioning. The research indicates that verbal questioning is a teaching method that classroom teachers use to involve students in classroom discussion and promote more interaction (Adedoyin, 2015). Foreign language teachers focus primarily on facilitating student learning and the acquisition of another language. However, this process requires classroom interaction and students' real involvement in order to be successfully achieved (Gillies, 2004). Kumpulainen and Wray (2002) asserted that: "It seems that in many contemporary classrooms social interaction is seen as a valuable tool for learning. The reasons for the growth interest in classroom interactions, and, more generally, in the processes of learning inherent in social interaction, reflect a theoretical shift in perspectives on learning and instruction." (p. 3). Creating classroom interaction requires the effective use of a variety of techniques and effective implementation of pedagogical intentions in order to develop teachers' understanding of the classroom interaction (Seedhouse, 1997). This can be achieved by understanding the types of features and events that occur in classroom settings that serve to facilitate the creation of classroom interaction. Using questioning behavior is one of the techniques teachers usually employ to promote and create classroom interaction (Lynch, 1991). We have noticed that teachers frequently and extensively use verbal questioning in EFL classes as a means of involving students in classroom discussions and creating interaction. However, some of these verbal questions fail to elicit the desired interaction while others succeed in doing so. Teachers therefore need to frequently adjust their questioning techniques in order to achieve the desired goals of the questions posed (Hussain, 2003). This study seeks to investigate interaction as a consequence of verbal questioning and to identify the questioning 
features that lead to classroom interaction. This study considers the following features of questions: a question's cognitive level, its complexity, its type (referential or display), and the communication pattern it tends to elicit. The same analysis will be made of questions that fail to achieve this goal. Hence, the main purpose of the study is to investigate the influence of effective questioning in fostering classroom interaction in EFL settings. As this study investigates features of questions that promote increased interaction according to cognitive level, complexity, question type - referential or display - and communication pattern. Pedagogically, this information can be useful to teachers when developing and executing lesson plans. By understanding the importance and role of questioning, instructors can formulate questions that promote an increase in classroom interaction and minimize the use of those questions that fail to do so.

\subsection{Research Question}

This study seeks to answer the following question:

Which types of questions are most influential in promoting and generating a greater amount of classroom interaction?

\subsection{Research Hypothesis}

This study has one hypothesis:

Some questions are expected to promote substantial classroom interaction more than others because of the questions' cognitive level, question complexity, question type - referential or display - and the communication pattern each question tends to elicit.

\section{Literature Review}

This section of the paper reviews literature on classroom interaction patterns and what strategies are adopted by teachers to create classroom interactions. It also discusses questioning techniques and how they impact EFL learners' interaction.

\subsection{Interaction in EFL Classroom}

Classroom interaction involves far more than students' ability to speak and express themselves. Classroom interaction encompasses any type of classroom participation occurring in the classroom such as teacher-student, student-student, group discussions and any other type of classroom participation. Walsh (2013) described interaction as a kind of communication that requires collective competence by all parties. With classroom interaction, teachers allow learners to interact and express themselves (Walsh, 2013). The teacher's role, therefore, is to enhance classroom interaction and guide students to become more reciprocal in their interaction (Nunan, 1991). Classroom interaction is desirable, especially in EFL settings, for a variety of reasons. Language teachers should engage their students with language and develop their language proficiency through classroom interaction (Van Lier, 1988). Moreover, interaction develops students' ability to engage socially outside of the classroom. Interaction can also help teachers to measure student progress and development. Successful classroom interaction however, requires considerable effort and management of numerous disparate classroom elements. Although many techniques help to foster classroom interaction, the primary focus of this research study is the utilization of verbal questions as a means of increasing classroom interaction.

\subsection{Participants in Classroom Interaction}

Classroom interaction encompasses the actions of both teachers and students inside the classroom. Classroom interaction is organized in different ways according to teachers' objectives and students' needs. Its organization depends on the participants who communicate together (Walsh, 2013), for example:

a) Teacher - learner

b) Teacher-learners

c) Learner - learner

d) Learner - learners

e) Learners - learners

Van Lier. (2014) mentioned that each type of classroom interaction presents different opportunities for interaction according to the participants' ability to interact and negotiate meaning. The above structures of interaction can be classified into two main types:

1) Teacher-Learner Interaction

2) Learner - Learner Interaction 
Teacher - Learner interaction takes place in the classroom between the teacher and students. It can be teacher-student or teacher- students' interaction. This form of interaction usually occurs when the teacher asks questions and one student answers the question. It also occurs when the teacher asks questions to small groups of students or the whole class and they respond to the question or questions. This type of interaction is usually controlled by the teacher who is the dominant figure in the classroom. The students' role is limited to providing answers and receiving commands. In this case, the class teacher is the sender and the students are receivers. The primary function of this type of interaction is to practice language in a controlled pattern. In most cases, the teacher's role in this type of interaction pattern is transmitting knowledge to students, because most of the patterns are in forms of modeling and drilling (Dagarin, 2004). The teacher initiates and ends the interaction and chooses the topic. In this interaction type, teacher talk time is a high proportion of available class time and studies show that it may last for as much as $(75 \%)$ of the total class time. Teacher-learner interaction usually follows the sequence of the Initiation - Response - Feedback (IRF), where the teacher initiates the interaction by asking a question and then closes the exchange by giving direct feedback. The student's output is limited to the response in the second turn only. Although that turn may involve extended language use, depending on the teacher's question, it is still controlled and lacks the pattern of the continuous conversation (Walsh, 2013). Here is an example of this structure in the classroom.

"T" Teacher Initiation: What is your favorite subject?

"R" Student Response: My favorite subject is biology.

"F" Teacher Feedback: Excellent.

This structure occurs commonly in classrooms worldwide. The teacher asks a question that has a direct answer, and the student provides a simple and direct answer in order to obtain a response- as to whether or not the answer is acceptable. The teacher closes the interaction by providing feedback. It is possible to extend the interaction by asking "why", but the interaction will still not be of significantly increased duration. This appears to be antithetical to one of the main goals of teaching which is sharing knowledge with students and allowing students to give and take in the classroom. Harmer (2017) asserted that teachers should encourage learners to produce communicative outputs and be engaged in communicative activities and that consequently, teacher's involvement should be minimized. The second structure of interaction is learner- learner interaction. This structure can be learner- learner, learner- learners, or learners- learners. This type of interaction occurs among learners in various ways. Learner- learner interaction is called 'pair work' and the other two types of interaction are called 'group work'. Learners interact together and the teacher's role is to monitor and guide students towards more organized progress in interaction. Studies show that students interact more in all types of learnerlearner interaction compared to teacher- learner interaction. Furthermore, students use more language functions in pair- and group-work than in other forms of interaction (Michael, Adams, McLean, \& Castaños, 1976). This structure is student- centered because the teacher acts as a facilitator; giving students increased responsibility and leading them to become increasingly independent. Moreover, this structure encourages the development of a more social class atmosphere. This student-centered structure also allows students to feel more comfortable and increases their willingness to talk more with their peers. This structure increases students' talk time and all members of the class add to the interaction according to the limits of his/ her language proficiency (Harmer, 2017). Furthermore, this structure allows students to have equal opportunities to produce increased output with their peers. The teacher's primary concern at this stage is to maintain all interaction in the target language and prevent students from reverting to L1. A considerable amount of research has been conducted regarding the use and limitation of the L1 in English classrooms and how to minimize or prevent its use in class. Al Sharaeai (2012) looked at the frequency of L1 use in English classrooms of 51 participants from different linguistic backgrounds and English proficiency levels in different English classrooms. Through online surveys and face-to-face interviews, participants agreed that they sometimes used the L1 to explain and ask about new ideas and concepts, whenever they felt they were not able to locate the correct word or expression in English, and as a means of maintaining the feeling of being somehow connected to their culture. Participants also mentioned that they use English more than their first language in English classes and that speaking English did not make them feel nervous. A clear connection was established between English language proficiency level and the responses generated in the online survey.

\subsection{Creating Classroom Interaction}

Classroom questions and activities are prepared by the teacher to achieve certain goals. These questions and activities are classified into two types: accuracy and fluency questions and activities. In both types, teachers' and students' roles differ. The teacher controls accuracy questions and activities and the students' role is limited to 
short answers in the form of drills. Teacher talk time dominates class time and such questions and activities are employed with the entire class or with individual teacher-nominated students. On the other hand, fluency questions and activities are concerned with allowing students increased time to talk and express their ideas and opinions. Teacher talk time is minimized and classroom interaction occurs for most of the lesson. Fluency questions and activities usually occur in pair or group work structures, which allow additional discussion time and the negotiation of meaning in EFL settings (Toni \& Parse, 2013).

\subsection{Strategies for Creating Classroom Interaction}

Teachers can use a variety of strategies to develop classroom interaction in a foreign language (Walsh, 2013). One way to increase classroom interaction is to encourage students to negotiate meaning when they do not understand what is required of them. Negotiation of meaning is a central aspect of classroom interaction, where learners actively involve themselves in interaction. Negotiation of meaning is defined as the verbal exchanges that occur when speakers seek to prevent the breakdown of communication (Ellis \& Barkhuizen, 2005). Interaction increases when negotiation of meaning occurs in the classroom between teacher and students or between students themselves. During negotiation of meaning, the input provided should be comprehensible. Otherwise, input should be repaired to allow the interaction process to proceed. Mackey (2007) asserted that incomprehensible input can be repaired in different ways through the processes of repetition, segmentation and rewording. Another means of increasing classroom interaction is through the use of scaffolding. Scaffolding is an instructional technique in which the teacher models the desired learning outcome or task, and then gradually shifts responsibility to the students. Teachers can use reformulation, extension or modeling to increase students' interaction and encourage their output. Scaffolding is often implemented by the teacher, who is considered the expert in the classroom. However, Van Lier. (2014) suggested that students can also scaffold by helping each other, as when strong students assist weaker peers in pair and group work. Samana (2013) studied teachers and students scaffolding in a university EFL classroom consisting of 14 volunteer students who were enrolled in an English course. The volunteers were both females and males aged 18 and 19, and each task was audio recorded. These students were regarded as being low level proficiency students because they were all repeating the course for a second time. The given task involved asking questions. Because the given task required working in pairs, students paired up with self selected partners. The teacher visited each pair of students to give assistance when they asked for help. The observations lasted for eight sessions. The results demonstrated that not only had the teacher provided scaffolding for the students, but students with low level of English proficiency had also successfully scaffolded their peers. Therefore, it can be said that is not necessary that scaffolding comes from an 'expert' or a teacher. Novices or students who are not fluent in English can also provide assistance when learning. Feedback can also be used to promote classroom interaction (Mackey, 2007). It can be written or verbal to indicate approval or disapproval of students' responses. Feedback can be used to encourage or criticize student output performance. Feedback supports learning and allows students to produce additional language during the process. Feedback usually refers to a specific knowledge or skill level and informs students of the appropriate manner in which to use the language in relation to a specific knowledge or skill.

\subsection{Questioning}

Asking questions in order to involve students in classroom interaction is the most common technique used by teachers in EFL settings. According to Walsh (2013), questions in educational settings are divided into two types according to the question's purpose: display and referential. Usually, teachers ask questions in order to elicit students thought and encourage students to elaborate on their ideas (Lemke, 1990). Through questions, teachers encourage students' talk and facilitate verbal interaction in the classroom, whether students' production is a single word, a sentence or longer utterances in conversational patterns. Qashoa (2013) studied the questioning behavior of EFL teachers in order to better understand how to design questions that can help expand students' knowledge and promote creative thinking. The participants involved in the study were three Arab teachers (a male and two females) of different nationalities, teaching in public secondary schools in the United Arab Emirates (UAE). The study found that the number of referential questions asked were less than the display questions. The study also demonstrated that display questions were used most frequently as class warm up activities, to review previous lessons and elicit factual information. However, longer student responses were elicited using referential questions. According to the researcher, both question types are useful in EFL classrooms and it would be risky to generalize that display questions are less useful since they elicit short answers or that referential questions are useful because they produce longer answers. Rather than make such a generalization, Qashoa (2013) contended that their use should be determined based on students' levels, lesson objectives and student learning strategies. 


\subsection{Impact of Teachers' Questions on Students' Learning in EFL Classrooms}

Numerous studies have pointed out the importance of teachers' questioning on the learning process in EFL classrooms. Teachers' questions are of significant value for many instructional purposes, such as eliciting student reflection and encouraging deeper student understanding and engagement in the classroom. Teacher questioning is an indispensible part of the teaching process (Cotton, 1988). Hamiloğlu and Temiz (2012) studied the impact of questioning behavior in two EFL classrooms from one private primary and one state primary school in Istanbul, Turkey. The results showed that there is evidence regarding the impact of teachers' questions on students' learning. Overall, the findings showed that the most preferred question type were Yes/No questions. Although the schools were different in their teaching strategies due to one being private and the other being state, there was not a significant difference in the schools' use of Yes/No questions (36 out of a total 98 questions). The reason behind the high usage of Yes/No questions is because these questions are generally simpler and thus are more appropriate for use with low proficiency level students. The study also showed that the least used teacher questioning technique was asking non-retrieval questions (total number of six in both schools). When compared, it was evident that there was a significant difference in the usage of Yes/No questions and non-retrieval questions. The study also showed the distribution of questions in terms of what purposes they fulfilled when asked in the classroom. Convergent questions, which serve for recalling background knowledge, but not for requiring higher-level thinking (Richards \& Lockhart, 2000), were the most frequently used questions (total number of 52) which was slightly more than double the divergent questions ( 28 of a total 98 questions posed in both schools). Procedural questions, which help establish classroom order in terms of classroom management and flow of teaching learning process, were the least used (18 of total 98 questions). These results show evidence of the impact of teachers' questions on student learning. The findings also show that in terms of the purposes of teachers' questions in class, convergent questions are mostly used with 52 out of a total of 98 questions. As these types of questions generally include Yes/No, short answer and display type questions, over-use of convergent questions are not favored in EFL. On the contrary, divergent questions are more challenging. These include open-ended, referential and non-retrieval/imaginative questions. To provide free production and active use of the target language, divergent questions are a more important and necessary means of classroom questioning. Santiago and Evnitskaya (2010) studied the questioning behavior of 4th English class in a high-school in Collserola, a mountain range between rivers in the Catalan Coastal Range. The class consisted of 28 students. Regarding the language level, there was considerable variation in students' English abilities. The study showed that there was a relative balance between student and teacher talk. Out of a total of 80 turns, students had 43 turns while the teacher had 37. However, many of the students' turns were simple nods or the raising of hands. Surrounding talk and unclear or unintelligible speech were also included in students' turn count which meant that teachers tended to produce longer and more complex speech stretches than the students.

\section{Research Methodology}

The research method adopted in this study was descriptive and qualitative in nature. Qualitative research uses methods such as participant observation or case studies which result in a narrative, descriptive explanation of a setting or practice. Using these methods typically rejects positivism and adopts the interpretive style (Drislane \& Parkinson, 2011). The research paradigm is interpretive, which is based on the idea that qualitative research efforts should be concerned with revealing several realities as opposed to searching for one objective reality. The essence of interpretivism is to work with the subjective meanings already evident in the social world and use them for building new theories. In this research, interpretivism is the dominant research paradigm, however; some quantitative data is used in order to create some classifications among questions' features and interaction occurrence frequency. For data collection purposes, classroom video recordings were used to investigate the features of the most influential questions in promoting significant classroom interaction.

\subsection{Research Instrument}

In the current study, an observational scale provided a measure of the quality of discourse facilitated during instruction in relation to features that promote classroom interaction. The observational scale was developed using The Electronic Quality of Inquiry Protocol (EQUIP) (Marshall, Smart, \& Horton, 2010), which is a highly reliable instrument designed to measure the quantity and quality of inquiry-based instruction. This inquiry protocol consists of five scales. The observational scale used here in order to examine the quality of discourse facilitated during instruction was adapted from EQUIP with minor modifications. The study is limited to certain features of the questions that promote increased interaction. Each scale is designed to measure specific constructs related to the quality of inquiry facilitated in the classroom. The scale is comprised of the following features: questioning cognitive level, complexity of questions, question type as referential or display and the communication pattern for each question. A detailed description is provided on the instrument for each feature 
for the following interaction levels: (1) beginner (level one interaction), (2) intermediate (level two interaction), (3) proficient (level three interaction), and (4) advanced inquiry (level four interaction). The scale was also be used to measure the cognitive level of questions. It provided a measure of the cognitive level of the teachers' questions. These cognitive levels are as follows: level 1-receipt of knowledge, level 2-lower order (recall, remember, understand), level 3 apply (demonstrate, modify, compare) and analyze (verify, justify, interpret), and level 4 create (combine, construct, develop, formulate). These levels are drawn from Bloom's Taxonomy (Krathwohl, 1964; Noble, 2004). Each type of feature that aids in the promotion of classroom interaction through questioning is supported with an extract example as evidence in the analysis section. The following table represents the scale used in the study.

Table 1. Analysis scale for features of interactive questions

\begin{tabular}{|c|c|c|c|c|c|}
\hline \multicolumn{6}{|c|}{ Analysis Scale } \\
\hline \multicolumn{2}{|c|}{ Measurements } & Level 1 & $\begin{array}{ll}\text { Level } & 2\end{array}$ & Level 3 & Level 4 \\
\hline \multirow{4}{*}{$\begin{array}{l}\text { Question } \\
\text { Features }\end{array}$} & $\begin{array}{l}\text { Cognitive } \\
\text { Level }\end{array}$ & $\begin{array}{l}\text { Questioning } \\
\text { rarely } \\
\text { Challenged } \\
\text { students on the } \\
\text { remembering } \\
\text { level }\end{array}$ & $\begin{array}{l}\text { Questioning } \\
\text { challenged } \\
\text { Students on the } \\
\text { understanding } \\
\text { level. }\end{array}$ & $\begin{array}{l}\text { Questioning } \\
\text { challenged } \\
\text { Students up to } \\
\text { application or } \\
\text { analysis levels. }\end{array}$ & $\begin{array}{l}\text { Questioning } \\
\text { challenged } \\
\text { students at } \\
\text { synthesis and } \\
\text { evaluation levels }\end{array}$ \\
\hline & $\begin{array}{l}\text { Complexity } \\
\text { Questions }\end{array}$ & $\begin{array}{l}\text { Questions } \\
\text { focused on one } \\
\text { correct answer; } \\
\text { typically short } \\
\text { answer } \\
\text { responses. }\end{array}$ & \begin{tabular}{l}
\multicolumn{2}{l}{ Questions } \\
focused mostly \\
on one correct \\
answer; some \\
open response \\
opportunities.
\end{tabular} & $\begin{array}{l}\text { Questions } \\
\text { challenged } \\
\text { Students to } \\
\text { explain, reason, } \\
\text { and/or justify. }\end{array}$ & $\begin{array}{l}\text { Students were } \\
\text { expected to } \\
\text { critique others' } \\
\text { responses. }\end{array}$ \\
\hline & $\begin{array}{l}\text { Types of the } \\
\text { question: } \\
\text { referential or } \\
\text { display }\end{array}$ & \multicolumn{2}{|c|}{$\begin{array}{l}\text { Display questions refer to questions } \\
\text { for which the questioner knows the } \\
\text { answer beforehand; such questions } \\
\text { are usually asked for comprehension } \\
\text { checks, confirmation check, or } \\
\text { clarification requests. }\end{array}$} & \multicolumn{2}{|c|}{$\begin{array}{l}\text { Referential questions are those } \\
\text { questions for which the answer is not } \\
\text { already known by the teacher such } \\
\text { questions require interpretations and } \\
\text { judgments on the part of the students. }\end{array}$} \\
\hline & $\begin{array}{l}\text { Communication } \\
\text { Pattern }\end{array}$ & $\begin{array}{l}\text { Communication } \\
\text { was controlled } \\
\text { and directed by } \\
\text { teacher and } \\
\text { followed a } \\
\text { didactic pattern. }\end{array}$ & $\begin{array}{l}\text { Communication } \\
\text { was typically } \\
\text { controlled and } \\
\text { directed by } \\
\text { teacher with } \\
\text { occasional input } \\
\text { from other } \\
\text { students; mostly } \\
\text { didactic pattern. }\end{array}$ & $\begin{array}{l}\text { Communication } \\
\text { was often } \\
\text { conversational } \\
\text { with some } \\
\text { student questions } \\
\text { guiding the } \\
\text { discussion. }\end{array}$ & $\begin{array}{l}\text { Communication } \\
\text { was consistently } \\
\text { conversational } \\
\text { with student } \\
\text { questions often } \\
\text { guiding the } \\
\text { discussion. }\end{array}$ \\
\hline Answers & $\begin{array}{l}\text { Interaction } \\
\text { Occurrence }\end{array}$ & $\begin{array}{l}\text { Teacher accepted } \\
\text { answers, } \\
\text { correcting when } \\
\text { necessary, } \\
\text { but rarely } \\
\text { followed-up with } \\
\text { further probing. }\end{array}$ & $\begin{array}{l}\text { Teacher or } \\
\text { another student } \\
\text { occasionally } \\
\text { followed-up } \\
\text { student response } \\
\text { with further } \\
\text { low-level probe. }\end{array}$ & $\begin{array}{l}\text { Teacher or } \\
\text { another student } \\
\text { often } \\
\text { followed-up } \\
\text { response } \\
\text { with engaging } \\
\text { probe that } \\
\text { required student } \\
\text { to justify } \\
\text { reasoning or } \\
\text { evidence. }\end{array}$ & $\begin{array}{l}\text { Teacher } \\
\text { consistently and } \\
\text { effectively } \\
\text { facilitated rich } \\
\text { classroom } \\
\text { dialogue where } \\
\text { evidence, } \\
\text { assumptions, and } \\
\text { reasoning were } \\
\text { challenged by } \\
\text { teacher or other } \\
\text { students. }\end{array}$ \\
\hline
\end{tabular}

The descriptors in this scale come from The Electronic Quality of Inquiry Protocol (EQUIP) (Marshall et al., 2010) (see Appendix B). 


\subsection{Participants}

The students in the foundation year program at the intermediate level are expected to be on B1 level of the CEFR, equivalent proficiency of 4.5 on IELTS and 57 on IBT TOEFL. The student participants in this study are native speakers of Arabic to whom English is a foreign language. All students had completed their high school education and were Foundation Year university students at the time of the study. Their average age was 18 .

Seven teachers participated in the study. The teachers were from different nationalities including Tunisian, Egyptian, British, Pakistani and Turkish. Their native languages varied accordingly. English was the native language for some, a second language for others and a foreign language for the remainder. Teachers' qualifications included MAs in TESOL, TEFL or English teaching with the exception of three teachers who had a bachelor degree with a CELTA or TEFL certificate. All teachers had EFL teaching experience ranging from five to 13 years including elementary/high school and post-secondary levels. In order to answer the research question, 11 classes from the seven teachers were video-recorded during a two-week period in the third module of the academic year 2014-2015. All participants in the study were males as the data collection occurred on the Men's Campus. Each class included 15 to 25 students.

\subsection{Data Collection}

Before the start of the data collection process, a formal request was forwarded to the Head of Higher Studies in order to gather data in the men's section of the university during Module 3 of the 2014-2015 academic year. Data was collected using video recordings after only subsequent to students' and teachers' permission to participate in the study having been obtained. The data collection came from teachers with different levels of experience and from various backgrounds. One session was recorded for four teachers and two sessions for the other three teachers which equaled ten hours in total. Each session recorded lasted between 30 and 50 minutes.

\subsection{Data Analysis Procedures}

The data analysis aimed to interpret and explain the data. The data was analyzed and interpreted in order to identify the most influential features of questions that promote classroom interaction. With regards to the video recordings analysis, the recordings were transcribed and analyzed using qualitative discourse analysis. All the data gathered was transcribed by a professional company. All transcriptions were undertaken and completed by trained personnel, using triple-pass quality assurance, in which a transcriber completes and proofreads a first draft. $\mathrm{He} / \mathrm{she}$ then forwards this first draft for editing to a supervisor, who listens to the entire audio from start to finish and verifies the transcript's accuracy. There is no software transcription involved, but Express Scribe is used as a tool to help start and stop audio during the manual process, and of course Word for the typing itself. Also, the transcriptions were also rechecked by the researcher. This study, does however, employ both qualitative and quantitative techniques to investigate what type of questions are used in EFL classes and to what extent they promote create classroom interaction. Counting and categorization techniques were used in some stages of the data analysis procedure.

\section{Findings}

This section presents the results of the data analysis undertaken in this study. After viewing and transcribing the videos, Moskowitz's Foreign Language Interaction Analysis (FLINT) system was used as an instrument to analyze classroom discourse. This analysis uses a standardized checklist. The FLINT checklist was used to transform the video data into a descriptive code. Each verbal behavior was given a numerical value representing the categories outlined in Moskowitz's instrument. The checklist was used for the purpose of coding each verbal interaction. As the following extract (see Table 2) illustrates,

Table 2. Extract 1 coding verbal interaction

\begin{tabular}{ll}
\hline Classroom Verbal Interaction & Recorded As \\
\hline T: Have you guys ever played Bingo? & 4 (Ask Questions) \\
L: No & 9 (Students' Response) \\
T: Thanks. Great & 2 (Praise) \\
\hline
\end{tabular}




\subsection{Questions}

This research investigates verbal questions asked by EFL teachers in the classroom. Analysis of the eleven lessons observed shows that verbal questions are the teacher's dominant talk pattern. A large number of questions are asked about main ideas and are not simply clarification or follow up questions. These questions are referred to as key questions. A total of 198 key questions are asked in the 11 recorded classes. The average number of key questions asked is 18 questions per class. The following table (see Table 3 ) shows the number of key questions asked in each lesson.

Table 3. Lessons' number of questions and duration

\begin{tabular}{lll}
\hline Lesson & Number of Questions Asked & Lessons Duration \\
\hline 1 & 21 & $48: 24$ \\
2 & 32 & 52.00 \\
3 & 28 & $58: 55$ \\
4 & 29 & $32: 36$ \\
5 & 14 & $57: 37$ \\
6 & 6 & $42: 21$ \\
7 & 10 & $53: 14$ \\
8 & 5 & $32: 32$ \\
9 & 11 & $55: 10$ \\
10 & 21 & $43: 58$ \\
11 & 19 & $01: 06: 31$ \\
\hline
\end{tabular}

The following graph (see Figure 3) shows the frequency of questions used in each class. The total number of questions asked is 198 key questions in 11different lessons with a total duration of nine hours and 12 minutes.

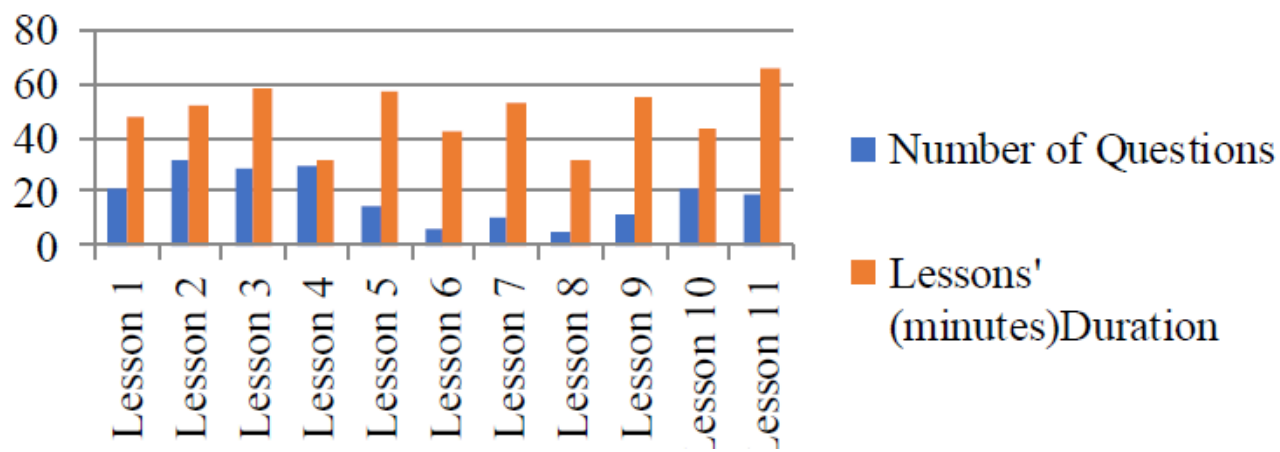

Figure 3. Duration and questions' occurrence in all lessons

\subsection{Interaction Occurrence}

Interaction occurrence was measured for each key question asked and classified into four interaction levels according to Marshall et al.'s categorization system (2010). The results demonstrate that the level of interaction differed depending on the question asked. SPSS program was used to identify the frequency of each interaction level as it occurred in response to each question. The following table contains the results (see Table 4). 
Table 4. Frequency of each interaction level

\begin{tabular}{lcc}
\hline Interaction Level & Frequency & Percent \\
\hline $\begin{array}{l}\text {-Teacher accepted answers, correcting when necessary, but rarely followed-up } \\
\text { with further probing. }\end{array}$ & $28.8 \%$ \\
$\begin{array}{l}\text {-Teacher or another student occasionally followed-up student response with } \\
\text { further low-level probe. }\end{array}$ & $35.4 \%$ \\
$\begin{array}{l}\text {-Teacher or another student followed-up response with engaging probe that } \\
\text { required to justify reasoning or evidence- }\end{array}$ & $24.7 \%$ \\
$\begin{array}{l}\text {-Teacher facilitated rich classroom dialogue where evidence, and reasoning were } 22 \\
\text { challenged by teacher or students }\end{array}$ & $11.1 \%$ \\
Total & 198 & $100.0 \%$ \\
\hline
\end{tabular}

The findings show that while the interaction occurs in all classes in response to verbal questions asked, the interaction levels vary from one question to another starting from low levels to advanced levels of interaction. The following figure illustrates the frequency of each level of interaction.

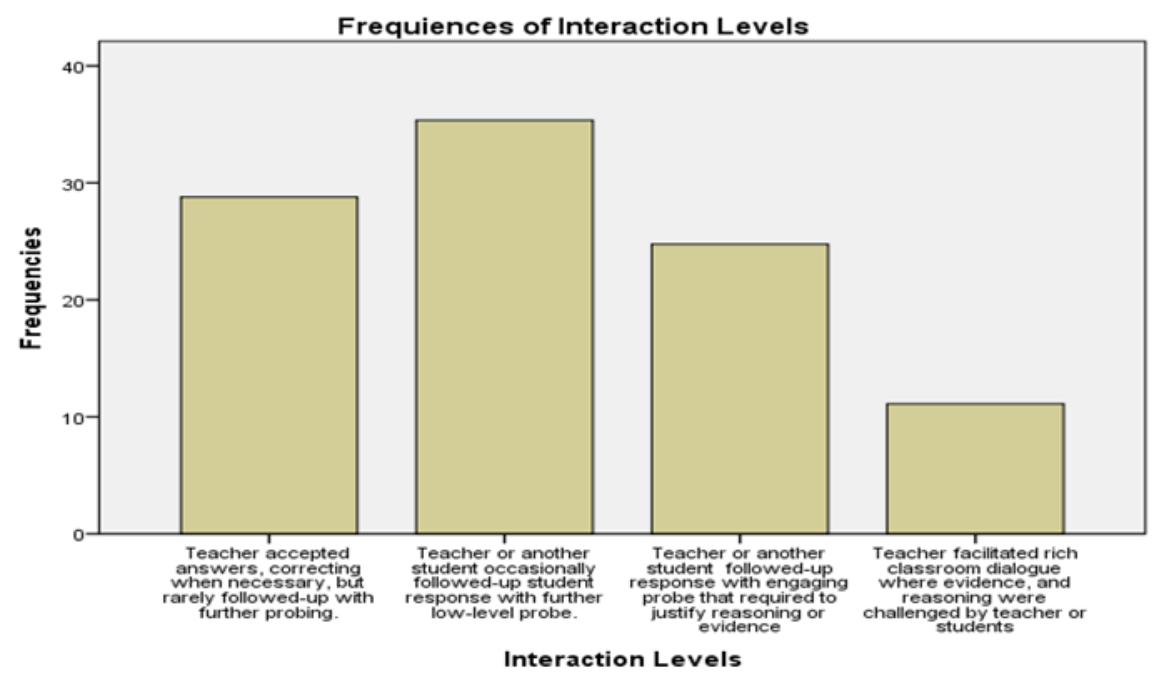

Figure 4. Frequency of each interaction level

The features of questions observed are further described in order to help teachers understand the factors that lead to each level of interaction and to assist teachers in selecting the desired level of interaction, according to students' proficiency level, teacher's pedagogical aim, and/or time constraints.

\subsubsection{Second Interaction Level}

It is apparent that the highest percentage of interaction occurrence observed in the study is "the second level of interaction where the teacher or another student occasionally followed-up on a student response with a further low-level probe" (Marshall et al., 2010). Second level of interaction occurs (35.4\%) of the time, followed by first level interaction at $(28.8 \%)$ of the time. First level of interaction occurs "when the teacher accepted answers, correcting when necessary, but rarely followed-up with further probing" (Marshall et al., 2010). Two examples illustrate the second level of interaction:

Extract 3: Level Two Interaction

1. $\mathrm{T}$ : is your room often a mess

Question

2. $\mathrm{L}:=$ yes $($.

Response

3. T: because of this you always forget your book?

Question

4. L: yes.

Response 
This example represents "the second level of interaction where the teacher or another student followed-up a student response with a further low-level probe" (Marshall et al., 2010). In this example, the teacher asks one question (line 1) and follows the student's response with another inquiry (line 3) which ends with one word reply "Yes" (line 4). The interaction is controlled but allows for low further contribution from the student.

Extract 4: Level Two Interaction

1. T: what is this?

Question

2. L: it is Kabsa

Response

3. T: do you eat it the morning, afternoon or evening?

Question

4. $\mathrm{L}:=$ yes (1) all the time.

Response

The second example (Extract 4) also exemplifies "the second level of interaction in which the teacher or another student followed-up a student response with a further low-level probe" (Marshall et al., 2010). Here, the teacher initiates the interaction by the first question asked (line 1) and provides a follow up question (line 3). The first question allows the student to answer the first question (line 2), and the second question gives the student the opportunity to provide more output by answering for the second time (line 4). These two probes are low in terms of length, turns and fluency. The second level of interaction occurs most often with $(35.4 \%)$ of questions resulting in this level of interaction. Regarding the questions resulting in second level interaction, it was found that these questions challenge students on their comprehension level (44.3\% of questions). (28.6\%) of questions which challenged students on application and analysis. Knowledge level questions occur $(24.3 \%)$ of the time. Regarding complexity level, (47.14\%) of questions challenge students to explain, reason, and/or justify. Other questions (32.8\%) focus on one correct answer; typically short answer responses. Additionally, the data shows that second level interaction is mostly created by display questions $(62.8 \%)$ and at a lesser rate by referential questions (37.14\%).

\subsubsection{First Interaction Level}

The lowest level (first level) of interaction comes as a result of 57 key questions asked and makes up (28.8\%) of the total number of questions. At "the first level of interaction, the teacher accepted answers, correcting when necessary, but rarely followed-up with further probing" (Marshall et al., 2010). Students' interaction is limited in terms of length, fluency and turn taking. Examples 5, 6 and 7 illustrate this level of interaction.

Extract 5: Level One Interaction

1. T: can anyone give me an example of an adjective?

Question

2. what's an adjective?

3. $\mathrm{L}$ : adjective (1) beautiful is adjective

Response

4. T: beautiful.ok/ok/ok

Give Information

5. okay, [inaudible 00:21:10], so adjectives, they normally describe

6. $\quad$ something, yes. They describe a noun, yes (.) yeah (.) This person is very

7. strong, he's very handsome, or something like this. You're just describing

8. somebody, or something (.) These we- these are adjectives, okay so now we

9. will look at the difference between base adjectives and strong adjectives.

In the example above (extract 5), the interaction takes the pattern of question and answer. The teacher asks a question (line 1) and receives an answer from the student (line 2). After that, the teacher accepts the student's response without giving any feedback or asking further questions. The interaction ends with the student answering and the teacher accepting the answer by elaborating and explaining what an adjective is (lines 4, 5, 6 , $7,8,9)$.

\section{Extract 6: Level One Interaction}

1. T: which word means frightened?

Question

2. L: terrified

Response

3. $\mathrm{T}:=\operatorname{good}$

Feedback

Extract 6 also provides an example of low (first) level interaction that occurs after the teacher asks a question (line 1). The interaction displays a regular pattern of inquiry, response and feedback. The student's turn is 
limited to the response he provides in the second turn (line 2). Although the teacher takes the turn again, the conversation finishes without him asking for further output from the student. It ends with direct feedback from the teacher (line 3).

\section{Extract 7: Level One Interaction}

1. T: what is the strong adjective of happy?

Question

2. L1: thrilled.

Response

3. L 2: delighted.

Response

4. T: thrilled (.) thrilled, yes, yes, yes (1) thrilled,

Feedback

5 .

thrilled and delighted, yes. It means very

6.

happy, very, very, yeah (.) thrilled or delighted,

7.

yes, it means very happy.

In extract 7, the interaction is also low level. When the teacher asks a question (line 1), student one answers (line 2) and his answer is followed-up by another student who answers the same question asked by the teacher (line 3 ). The teacher does not provide any further opportunity for extending the interaction, but gives immediate feedback to confirm the students' answers. This is due to the teachers' pedagogical aim of asking questions to review new vocabulary learned in the lesson. In some instances, "low classroom interaction occurred because teachers corrected students' responses but rarely followed-up with further probing" (Marshall et al., 2010). The first level of interaction is the second most frequent level of interaction that results from teachers' questions. Most of the questions $(59.6 \%)$ which create low level interaction challenge students mainly by means of lower level cognitive questions such as comprehension. However, some questions challenge students' knowledge levels (35\%). Regarding 'the complexity of questions', it is apparent that the majority of the questions (91.2\%) "focused on one correct answer; typically short answer responses" (Marshall et al., 2010) which corresponds to the lowest complexity level.

In terms of questions type, a large number of display questions were used (98.2\%) which create low level interaction. Furthermore, it is apparent that the communication pattern of the majority of questions $(92.9 \%)$ are controlled and directed by teacher and follow a didactic pattern which is the lowest communication pattern according to Marshall et al. (2010).

\subsubsection{Third Interaction Level}

Around $25 \%$ of the questions asked resulted in the third level of interaction. At "the third level of interaction, the teacher or another student often followed response with an engaging probe that required students to justify their reasoning or provide evidence" (Marshall et al., 2010). At this level of interaction, students' contribution and involvement in the classroom increased. The data show that "the teacher often followed-up on students' responses with engaging probe that required the students to justify, reasoning or evidence" (Marshall et al., 2010). Students provide justifications in response to the teacher's further probes (lines 28, 37, 45, 50, 55). Students justify helping orphans, aiding poor people, visiting different countries and starting a business in response to the teacher's continued questioning. The teacher's follow up questions work as engaging probes that encourage students to think of further responses and add more to the conversation that began with the first question asked (line 1). The use of further probing questions help teachers to elicit discussions, come up with new ideas, or create opportunities for thinking outside the box. Engaging questions allow students to be more involved in thinking and learning which, consequently lead to increased levels of classroom interaction. It is clear that students' proficiency levels play a critical role towards achieving the third interaction level. In the above extract, students are at B1 CEFR level. This proficiency level allows them to achieve this interaction level at certain times, but this proficiency is not the clearly uniformly evident as the dominant interaction level in the observed classes. According to the data analysis, the most predominant number of questions that result in third level interaction are questions that challenge students at 'application' and 'analysis' cognition levels (34.7\%) or challenge students' comprehension (30.61\%). In addition, (24.5\%) of questions that result in this level of interaction are questions that challenge students' cognitive level of 'knowledge'. Regarding 'question complexity', (55.1\%) of the questions that lead to this level of interaction "challenged students to explain, reason, and/or justify" (Marshall et al., 2010). Also, questions that focus mostly on one correct answer; with some open response opportunities account for $(20.4 \%)$ of the questions in this category, while questions that had only "one correct answer; typically short answer responses" (Marshall et al., 2010) recounted for (16.32\%). In relation to the question types at this level of interaction, both display $(57.14 \%)$ and referential questions $(42.85 \%)$ create 
third level interaction. Regarding question communication pattern, conversational communication pattern mostly occurs at the third interaction level. Questions asked are sometimes created by "questions that are controlled and directed by teacher with occasional input from other students; mostly didactic pattern" (Marshall et al., 2010) $(28.57 \%)$.

In conclusion, the "third level of interaction, where the teacher mainly followed-up response with engaging probe that required student to justify reasoning or evidence" (Marshall et al., 2010), is created by the questions that challenge students on application and analysis levels or the comprehension level. The questions that result in third level interaction are both display and referential and challenge students to provide explanation, give reasons, and/or offer justifications. Also, questions that promote the third level of interaction are conversational.

\subsubsection{Fourth Interaction Level}

The least frequently occurring level of is 'the fourth (highest) level', which requires "the teacher to consistently and effectively facilitate rich classroom dialogue where evidences, assumptions and reasoning are constantly challenged" (Marshall et al., 2010). Level four interaction is created as a result of 22 questions out of the total number of questions. Level four interaction represents (11.1\%) of the entire interaction across all observed EFL classes. The findings indicate that "the fourth level of interaction where the teacher consistently and effectively facilitated classroom dialogue where students' assumptions" (lines 23, 24, 25), "and reasoning" (line 20) "were challenged by the teacher and other students" (Marshall et al., 2010). It is apparent that many students take regular turns during the dialogue. In some turns, students push the conversation further by asking questions (lines 11, 18, 32). Also, students express their opinions, give examples and discuss the topic in-hand with their teacher and peers. Although incomplete sentences are sometimes used, the speech flow continues toward more meaningful speech. Students are also encouraged to be involved in the classroom discussion by further questions asked by the teacher (Lines 2, 3, 7, 14, 19, 22, 26, 30,33). The dialogue is lengthy with numerous teacher's and students' turns. Also, students demonstrate a higher proficiency level compared to the language produced in the previous three interaction levels. The features of questions that created the fourth (advanced) level of interaction must be further described to help teachers formulate and utilize these questions more frequently. According to the data gathered, it is apparent that the cognitive levels of the 22 questions that lead to fourth level of interaction vary, however the majority of these questions challenge students at the 'synthesis' and 'evaluation' cognitive levels $(36.4 \%)$. Also, $(31.8 \%)$ of the questions that result in this level of interaction challenge students at the 'application' or 'analysis' cognition levels. This analysis demonstrates that teachers should aim to formulate questions that focus on students' ability to synthesize, evaluate, apply or analyze when they wish to promote high interaction levels. The desired interaction level for a specific lesson is determined by the teacher's lesson or particular phase in the lesson, goal, time constraints, students' proficiency level and any other factors the teacher may wish to take into consideration. Regarding 'the complexity level of the questions' used, it is apparent that the majority of "questions that created advanced classroom interaction encouraged students to explain, reason or justify" (Marshall et al., 2010). This complexity level occurs in (50\%) of the questions observed at the fourth interaction level. The other (50\%) of questions (11 questions) are a mixture of the other complexity levels.

\subsection{Comparison of Interaction Levels in Each Class}

The questions' frequency varied from one lesson to another and interaction levels varied accordingly. The data show that the level of interaction that occurs most frequently (in 5 classes) is the second interaction level. The second most frequent type of interaction observed is level one interaction, occurring in three classes. Interaction levels three and four dominate only in two classes. This indicates that, while it is possible for all four interaction levels to occur in ELI EFL classrooms, level two interactions usually occur with most frequency among all interaction levels observed in ELI EFL classes. Level four interaction (most advanced level of interaction), occurs least frequently in classrooms observed. In "level four interaction, teacher consistently and effectively facilitated classroom dialogue where evidence, assumptions, and reasoning were challenged by teacher or other students" (Marshall et al., 2010). The reasons for this result may be due to the high proficiency level required for this level of interaction to occur. Students' perceived proficiency appears to be below the level required for this level of interaction and they may well lack the necessary lexical and grammatical range and accuracy required for such interaction. On the other hand, the occurrence of level one interaction was also low. "Teachers accepted answers, correcting when necessary, but rarely followed-up with further probing" (Marshall et al., 2010). This level of interaction is fairly straightforward and students enrolled in level 104 (intermediate level) interact at a higher level than this. Level three interaction is lowest in only two classes, and level two is the lowest in only one class. This indicates that these two types of interactions commonly occur in ELI EFL classrooms with students whose language proficiency level is ELI 104, B1 CEFR. 


\section{Discussion}

This section discusses the key findings of this study in relation to the features of verbal questions asked in ELI EFL classrooms and their resulting interaction levels when compared to the previous studies presented in the literature review.

\subsection{Findings of Study Compared with Previous Scholars' Findings}

The findings of this research study indicate that the levels of classroom interaction in EFL contexts can be significantly enhanced through the judicious use of questioning techniques. Questioning techniques are demonstrated as being widely used in the observed EFL classrooms. This is consistent with Qashoa's study (2013) which revealed that teachers engage in a large amount of questioning since questioning is a key tool for classroom instruction and evaluation in classrooms. The data collected also confirmed that the use of the questioning techniques used in English classes helped students become more involved in classroom interactions. While questioning was found to be a dominant feature of EFL classrooms, interaction occurred in different levels depending on the question asked. Furthermore, interaction seemed to vary between low and high levels of interaction when verbal questions were posed, depending on students' proficiency level, pedagogical goals and time constraints. Observation of the classroom videos indicates that while third level interaction is not the most frequently used, it occurs at an average frequency. "At third interaction level, the teacher or another student often followed-up responses with engaging probes that required student to further justify their reasoning or provide evidence" (Marshall et al., 2010). This level of interaction is created by questions that challenge students on the cognitive levels of analysis and application. It is a logical assumption that high cognition level questions such as analysis and application would lead to higher interaction levels. This result is consistent with the findings of (Moghaddam, Ghabanchi, \& Malekzadeh, 2011) where the more proficient a student is, the more likely he or she is able to engage in higher-level cognitive processes such as evaluation. Learning outcomes for these cognitive level questions require a higher intellectual level of understanding than simple comprehension because they require an understanding of both the material's content and structural form. Moreover, this interaction level is created by use of both display and referential questions. According to this research study, the second level of interaction is the most commonly observed among all classes recorded. "In the second level of interaction, the teacher or a student occasionally follows-up a student response with a further low-level probe" (Marshall et al., 2010). Students interact at second level of interaction when the questions asked challenge their comprehension. This might be due to the learning outcomes of this cognitive level which go beyond simple memorization and recollection of material, representing the lowest level of understanding in the cognitive domain. Moreover, this interaction level is created by display questions. Display questions are usually asked as comprehension checks, confirmation checks, or clarification requests. Lastly, the first interaction level (lowest level) occurs with average frequency in the EFL classes observed. First interaction level is mostly created by the use of second level cognitive questions that challenge students on comprehension. Questions that create "the lowest interaction level focus on one correct answer; typically, short answer responses" (Marshall et al., 2010).

In this study, findings show that only display questions create level one interaction. This is consistent with Ribas' study (2010) which found that display questions often prevent students from expressing their own ideas and are likely to encourage the repetition of facts or pre-formulated language items. However, these findings contradict the finidings of David (2007), who found that referential questions do not create much opportunity for teacher-pupil exchanges and that referential questions give students the chance to express their feelings and, consequently, generate much longer, complete sentence stretches. He argued that display questions promote increased classroom interaction among school students and may work to encourage learners', especially beginners, interest and participation in English classrooms. Nevertheless, these contradictions are addressed by Walsh's argument (2013) that both referential questions and display questions should be associated with the pedagogical goals of the teacher at the time of the lesson.

The complexity level, communication pattern and question type of level one questions eliminate the possibility of any higher interaction taking place because questions require students to produce language that is restricted in terms of length, accuracy, and fluency. This interaction level suggests that students are incapable of extending their speech to higher levels due to their proficiency level. In this study, first interaction level occurs at an average rate possibly because of the teachers' pedagogical goals. The interaction that occurs in the classrooms allows students to learn and produce the language in a social process which plays an essential role in evolving learners' cognition and learning improvement according to Vygotsky's Zone of Proximal Development (ZPD) and social cultural theory (Chaiklin, 2003). 


\subsection{Most Influential Types of Questions in Promoting Classroom Interaction}

One of the major aims of this study is to investigate the specific features of verbal questions as they relate to interaction. While questions have many features, this study focuses on cognitive level, question type, complexity and communication pattern. The analysis of this study reveals that interaction occurrence is affected by a question's complexity. The higher the level of a question's complexity is reflected in resulting increased interaction occurrence. Extracts provided in the findings chapter demonstrate the manner in which the questions asked, vary according to complexity which leads to variation in classroom interaction and involvement levels in EFL classrooms. This indicates that merely asking additional questions does not of itself necessarily lead to higher participation or more interaction. Furthermore, it is important to recognize the correlation between students' proficiency level (B1 CEFR) and the complexity of questions asked. The majority of classes observed display second level interaction. This means that for the most part the complexity of the questions asked and the proficiency level of students are in the same range. In other words, the complexity of questions should match their proficiency level. This supports Skelton and Meyer (1992) who proved that low proficiency level students tended to ask and reply to confirmation check questions and clarification requests, while high proficiency level students asked and replied to questions that required reasons and justifications. Additionally, the data analyzed in this research finds that there is a correlation between the cognitive level of questions and observed interaction levels. When higher cognitive level questions are posed, correspondingly high proficiency levels are needed by students to formulate appropriate responses. For example, when a question challenges a student at a cognitive level that they have not yet attained, interaction rarely occurs. The findings also note that there is a relationship between the communication pattern of questions and the interaction levels. Interaction levels simultaneously increase as the communication pattern increases. Meaning, "the communication pattern" gradually moves from "teacher controlled communication" to "a conversational pattern where the students guide the discussion" (Marshall et al., 2010). Furthermore, the proficiency level of students impacts the communication pattern observed. Generally, students of low proficiency are not able to produce higher communication patterns. For example, in this study students of proficiency level B1 are rarely able to produce conversational pattern with students guiding the discussion. Another feature investigated in the study is question type. While scholarly views differ on the type of questions that create increased interaction, the majority of questions used by teachers in this study are display questions due to the teachers' pedagogical goals (accuracy over fluency). These display questions result in various interaction levels. This points to the reality that interaction levels created by question type are influenced by a question's complexity and its communication pattern. For example, when display questions are asked, they create level one, two, and three interaction. The interaction level prompted and created by such display questions increases in tandem with complexity and communication patterns. On the other hand, referential questions create the highest levels of interaction including levels three and four. By their nature referential questions require additional elaboration and discussion. As displayed in the previous features, proficiency level has an impact on question type. Students with low proficiency levels are less likely to be able to answer referential questions, because referential questions require more engagement from students such as expressing their thoughts and sharing their experiences. Ultimately, the overall findings lead to the acceptance of the hypothesis that some questions are expected to promote a more substantial quantity of classroom interaction because of their cognitive level, complexity, type and communication pattern. The current study demonstrates the relationship between classroom discourse, specifically teacher questioning, and the level of consequently occurring classroom interaction. Teachers have the unique opportunity to create higher interaction levels through the questions they ask during their lessons. The first step for teachers is to be aware of the impact that their questioning strategies have on students' involvement in the classroom and their language use and practice. Initially, teachers should establish a target level of interaction for their students according to their proficiency level and pedagogical goals. Once a desired interaction level is chosen, the teacher should aim to gradually improve students' ability to interact at the subsequent interaction level. Shaping the appropriate questions means that teachers need to take into account question features (cognitive level, complexity, type and communication pattern) in order for the desired interaction to occur. Teachers need to plan the specific questions they will ask before they begin any instruction. It can be concluded that developing higher-order questioning requires teachers to be more flexible in their instructional practices (Marshall, Smart, \& Horton, 2009; Marshall et al., 2010). Teachers with higher levels of knowledge and awareness are more comfortable with questions that require students to engage with a higher level of cognition and interaction. This makes learning as a social process that demands natural interaction among all parties. Vygotsky's social cultural theory corresponds with the findings, in which the social interaction is developed in the classroom. Teachers who always rely on questions with a specific, pre-determined answer are not aware of the role of questions in improving and enhancing students' involvement and interaction. 


\section{Conclusion}

The research concludes that verbal questions asked, generate different interaction levels according to the questions' features: cognitive level, complexity, type and communication pattern. English language proficiency level also appears to have a direct connection to the types of responses generated in reply to questions. The higher the proficiency level of the participants, the higher the level of interaction that occurs. With lower interaction level, students seem unable to employ the needed structure and vocabulary. It is apparent that they sometimes rely on their first language to express themselves or resort to periods of silence as a result of their classroom predicament. Additionally, it is noticed that such low proficiency level students display increasing anxiety when asked to use only English in the classes. These factors of language proficiency and first language use need to be explored further to ascertain their full connection to the level of interaction occurrence in English classes.

\section{References}

Adedoyin, O. (2015). An Investigation of the Effects of Teachers' Classroom Questions on the Achievements of Students in Mathematics: Case Study of Botswana Community Junior Secondary Schools.

Al Sharaeai, W. A. A. (2012). Students' perspectives on the use of L1 in English classrooms.

Brown, H. (2006). Teaching by Principles: An Interactive Approach to Language Pedagogy. New J ersy: Prentice Hall Regents. In W. C. Wu (Ed.).

Chaiklin, S. (2003). The zone of proximal development in Vygotsky's analysis of learning and instruction. Vygotsky's educational theory in cultural context, $1, \quad 39-64$. https://doi.org/10.1017/CBO9780511840975.004

Cotton, K. (1988). Classroom questioning. Northwest Regional Educational Laboratory. Paper presented at the The Office of Educational Research and Improvement (OERI), US DepartmentofEducation. http://www. learner. o rg/workshops/socialstudies/classroomquestioning/pdf. accessed on April 22nd 2014.

Dagarin, M. (2004). Classroom interaction and communication strategies in learning English as a foreign language. ELOPE: English Language Overseas Perspectives and Enquiries, 1(1-2), 127-139. https://doi.org/10.4312/elope.1.1-2.127-139

Dalton-Puffer, C. (2007). Discourse in content and language integrated learning (CLIL) classrooms (Vol. 20): John Benjamins Publishing. https://doi.org/10.1075/1llt.20

David, O. F. (2007). Teacher's Questioning Behaviour and. Humanity \& Social Sciences Journal, 2(2), 127-131.

Drislane, R., \& Parkinson, G. (2011). Qualitative research. Online dictionary of the social sciences.

Ellis, R., \& Barkhuizen, G. P. (2005). Analysing learner language: Oxford University Press, USA.

Gillies, R. M. (2004). The effects of cooperative learning on junior high school students during small group learning. Learning and instruction, 14(2), 197-213. https://doi.org/10.1016/S0959-4752(03)00068-9

Hamiloğlu, K., \& Temiz, G. (2012). The impact of teacher questions on student learning in EFL. Journal of Educational and Instructional Studies in the world, 2(2).

Harmer, J. (2017). The practice of English language teaching.

Hussain, N. (2003). Helping EFL/ESL students by asking quality questions. The Internet TESL Journal, 9(10).

Krathwohl, D. R. (1964). Taxonomy of educational objectives: The classification of educational goals (Vol. 2): Longmans, Green.

Kumpulainen, K., \& Wray, D. (2002). Classroom interaction and social learning: From theory to practice: Psychology Press.

Lemke, J. L. (1990). Talking science: Language, learning, and values: ERIC.

Long, M. H., Adams, L., McLean, M., \& Castaños, F. (1976). Doing things with words: Verbal interaction in lockstep and small group classroom situations. On Tesol, 76, 137-153.

Long, M. H., \& Sato, C. J. (1983). Classroom Foreigner Talk Discourse: Forms and Functions of Teachers' Questions.

Lynch, T. (1991). Questioning roles in the classroom. ELT Journal, 45(3), 201-210. https://doi.org/10.1093/elt/45.3.201 
Mackey, A. (2007). Conversational interaction in second language acquisition: a series of empirical studies: Oxford University Press.

Marshall, J. C., Smart, J., \& Horton, R. M. (2010). The design and validation of EQUIP: An instrument to assess inquiry-based instruction. International Journal of Science and Mathematics Education, 8(2), 299-321. https://doi.org/10.1007/s10763-009-9174-y

Moghaddam, M. M., Ghabanchi, Z., \& Malekzadeh, S. (2011). The study of EFL teacher discourse in reading skill using Bloom's cognitive taxonomy. International Journal of Linguistics, 3(1), 18. https://doi.org/10.5296/ijl.v3i1.812

Noble, T. (2004). Integrating the revised Bloom's taxonomy with multiple intelligences: A planning tool for

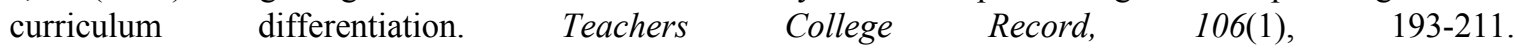
https://doi.org/10.1111/j.1467-9620.2004.00328.x

Nunan, D. (1991). Language teaching methodology: a textbook for teachers: Prentice Hall.

Qashoa, S. H. (2013). Effects of teacher question types and syntactic structures on EFL classroom interaction.

Samana, W. (2013). Teacher's and Students' Scaffolding in an EFL Classroom. Academic Journal of Interdisciplinary Studies, 2(8), 338. https://doi.org/10.5901/ajis.2013.v2n8p338

Santiago, M., \& Evnitskaya, N. (2010). The effects of teacher talk on students' oral productions.

Seedhouse, P. (1997). The case of the missing "no": The relationship between pedagogy and interaction. Language learning, 47(3), 547-583. https://doi.org/10.1111/0023-8333.00019

Toni, A., \& Parse, F. (2013). The status of teacher's questions and students' responses: The case of an EFL class. Journal of Language Teaching and Research, 4(3), 564-569. https://doi.org/10.4304/jltr.4.3.564-569

Van Lier, L. (1988). The classroom and the language learner: ethnography and second Language classroom research: Longman.

Van Lier., L. (2014). Interaction in the language curriculum: Awareness, autonomy and authenticity: Routledge.

Walsh, S. (2013). Classroom discourse and teacher development: Edinburgh University Press.

\section{Copyrights}

Copyright for this article is retained by the author(s), with first publication rights granted to the journal.

This is an open-access article distributed under the terms and conditions of the Creative Commons Attribution license (http://creativecommons.org/licenses/by/4.0/). 